\title{
Women's Desire for Freedom and Power Motive: A Study
}

\author{
Dr. Lakshmi Pandey ${ }^{1 *}$, Bi. Shabila ${ }^{2}$
}

\section{ABSTRACT}

Women have changed; they entered into a world previously occupied solely by men. In recent decades, more and more women have achieved notable progress in occupations previously reserved for men. The present study aimed to examine the relationship between women's desire for social freedom and power motive among college going girls. The study was conducted on a sample of 200 college going girls in the age range from 18-26 years who were enrolled in a large university of Bihar. WSF scale developed by M. Saha and power motive inventory developed by H.Ojha were employed to capture responses. Result shows that women with high and low WSF score had differing significantly with respect to their need for power motive. Results also indicate that all educated girls had a moderate level of WSF score and moderate urges of power motive. Thus, findings revealed that co-efficient of correlation between the scores of WSF and power motive among girls was positive and significant at .01 level.

\section{Keywords: Women's Desire for Freedom, Power Motive \& Educated Girls}

The status of women in India has long been paradoxical. They have had access to professions such as medicine, teaching and politics and have the right to own property. Among some social classes, women are extremely powerful. Women have been taking increasing interest in recent years in income generating activities, self-employment and entrepreneurship. This is seen in respect of all kinds of women both in urban and rural areas (Rajini, 2008). Women are taking up both traditional activities (Knitting, pickle making, toy making, jam and jelly making) and also non-traditional activities (like computer training, catering services, beauty parlor, gym etc.).

The economic, social, religious, cultural and psychological factors affect origination and success of women empowerment (Habib, Roni \& Haque, 2005). The reasons and motivations for starting business or economic activities by rural women are enormous. The important reasons are earning money or attractive source of income, enjoying better life, availability of loans, favorable government policy, influence of success stories, personal satisfaction, desire to utilize own skill

\footnotetext{
${ }^{1}$ Assistant Professor (Sr. Scale) of Psychology; B.N. College, Bhagalpur, TMBU, Bhagalpur, BIHAR (INDIA)

${ }^{2}$ Research Scholar, Dept. of Psychology, TMBU, Bhagalpur, BIHAR (INDIA)

*Responding Author

(C) 2016 I L Pandey, B Shabila; licensee IJIP. This is an Open Access Research distributed under the terms of the Creative Commons Attribution License (http://creativecommons.org/licenses/by/2.0), which permits unrestricted use, distribution, and reproduction in any Medium, provided the original work is properly cited.
} 


\section{Women's Desire for Freedom and Power Motive: A Study}

and talents, unfavorable present working environment, self-employment and employment to others, assurance of carrier and family security, fulfillment of creative urge of the borrowers' experience in family business, self-confidence, non-ability to find suitable job or work,

However, due to the traditional practices and customs the status of women has not improved much. Some women have felt that traditional values and practices are interfering and restrictive in the development of their personality. They have started protesting against the traditional values and are trying to break through the old values. The women who are actively engaged in protesting social norms and restrictions against women are the modern women. They have strong urge for social freedom. But there are a good number of women who have little urge for social freedom and are happy in leading a traditional way of life there is individual differences in the urge for social freedom in women. Free participation of women in the National Development Plan is the need of the hour. The modern women have changed their outlook and attitudes to social issues, norms etc. in the interest of the development of the nation. The urge for social freedom in women has its importance in the life of women as well as the nation.

Women's Desire for Social Freedom: Literally the desire for social freedom is a desire to get rid of responsibilities and restrictions which are uneasy and unpleasant. But in recent years, it does not necessarily mean the desire to get rid of a responsibilities or traditional roles with a number of restrictions. In fact, it is a desire to achieve equality and liberty in social life. Equality means equal treatment to all section or treats every person or group of persons as human being. Discrimination in treatment to son and daughter, rich and poor etc. is unjust. Privileges and opportunities must be offered to all on equal terms. Liberty stands for independence and freedom to act upon one's impulse. Freedom is necessary for full growth of one's potentialities and personality. So anything which goes against the principle of equality and liberty is the source of dissatisfaction.

Women's desire for freedom is born of the feminine spirit, which is the absolute, elemental, inner urge of womanhood. It is the strongest force in her nature; it cannot be destroyed; it can merely be diverted from its natural expression into violent and destructive channels. The chief obstacles to the normal expression of this force are undesired pregnancy and the burden of unwanted children. These obstacles have always been and always will sweep aside by a considerable proportion of women. Driven by the irresistible force within them, they will always seek wider freedom and greater self-development, regardless of the cost. The sole question the society has to answer is how shall women be permitted to attain this end?

Society, in dealing with the feminine spirit, has its choice to clearly defined alternatives. It can continue to resort to violence in an effort to enslave the elemental urge of womanhood, making of woman a mere instrument of reproduction and punishing her when she revolts. Or, it can permit her to choose whether she shall become a mother and how many children she will have. It 


\section{Women's Desire for Freedom and Power Motive: A Study}

can go on trying to crush that which is uncrushable, or it can recognize woman's claim to freedom and cease to impose diverting and destructive barriers. If we choose later course, we must not only remove all restrictions upon the use of scientific contraceptive, but we must legalize and encourage their use.

Freedom and control are two opposite situations. But, both freedom and control are regarded important for existence and power growth. Women desire for social freedom is concerned with the grievances of women against men who are in privileged positions and treat women as their subordinates. In the words of Bhusan (1987) women's desire for social freedom means women's desire to be free from social taboos, conservative rituals and roles which provide them a lower status in the society. Many studies have revealed that women of today have become conscious of their lower status, which they consider man made and unjustified. The roles assigned to women are not in accordance with their merit and privilege allowed to them doesn't in accordance to the services hey render to the family and society. In the Indian context, a number of studies have revealed how girls are discriminated from boy's right from their birth (Baic, 1976; Leopard, 1976; Nanda, 1976; Kapur, 1979). Some modern women are eager to uplift their status equal to men and wish to be independent in many respects.

Nevertheless, women have changed; they entered into a world previously occupied solely by men. In recent decades, more and more women have achieved notable progress in occupations previously reserved for men. As women have moved from domestic to paid labour in a workplace, their aspirations, attitudes and performance have changed and improved dramatically. This runs parallel to their occupation in previously male-dominated functions, positions and roles. Women today have achieved educational levels compared to men and are an economic force with buying power of their own. As a result of their newly gained freedom Indian women have distinguished themselves in various spheres of life as politicians, orators, lawyers, doctors, teachers, administrators and diplomats. They are not only entrusted with work of responsibility, but also they perform their duties very honestly and sincerely. It is a fact that women are intelligent, hard-working and efficient in work. They put heart and soul together in whatever they undertake. There is hardly any sphere of life in which Indian women have not taken part and shown their worth. Women exercise their right to vote, contest to Parliament and Assembly, seek appointment in public office and compete in other spheres of life with men. This shows that women in India enjoy today more liberty and equality than before.

Power motive: The Power motive is conceived as a desire to acquire status and have an impact on others, thus affecting their behaviour and emotions (winter, 1992). In the more general meaning of the term, it is identified with a factor that is fundamental to the conception of leadership, namely the motivation to acquire and to exert social influence, so that possessing a certain amount of power would appear to be a necessary requirement to be an effective leader. Power as an influence on behaviour is shedding some of its long-standing mystique as more

(C) The International Journal of Indian Psychology, ISSN 2348-5396 (e)| ISSN: 2349-3429 (p) | 175 


\section{Women's Desire for Freedom and Power Motive: A Study}

people admit they like it, want it, enjoy it, and desire more of it. Even more intriguing is the fact that power has been considered a masculine trait and carried the connotation of dominance, aggressiveness and competition, whereas women have been described as submissive, cooperative and passive. These differences are the result of a pre-determined pattern of socialization of boys and girls and the roles that are ascribed to them across the life span from birth to senescence.

Over the last 15 years, two significant changes have been occurring that give a somewhat different perspective to the concept. One is that power is a facilitating factor as demonstrated when individual, whether male or female, strives to influence others in the achievement of organisational goals. This form of power, known as socialised power, is present in those managers who are most successful in their leadership roles. In contrast, personal power serves as an inhibiting factor when an individual seeks to achieve individual goals at the expenses of others or organisation. There is some empirical evidence to indicate personal power is associated with unfavourable behaviours such as excessive drinking, aggressive behaviour and sexual and personal exploitation.

Power motive is one of the social motives based on McClelland's theory of human motivation: a concern for impact, which is associated with a need to acquire social status and prestige (McClelland, Davis, Kalin\& Wanner, 1972; McClelland, 1975). Power motives refer to individual differences in the human tendency to be dominant and to achieve control over means that can be used to influence other individuals (Veroff, 1957). Striving for status, dominance, superiority, or controlling positions are thus typical of manifestation of the power motive (Winter, 1973). For both men and women, the power motive predicts both carrier plans and later carrier behavior (McClleland, 1985b; Winter, 1973, 1988). Winter and Stewart's, (1976) define the power motive as the desire for power or for the feelings associated with having power. The goal state of the power motive is the experienced satisfaction of having an impact on other people that is, both feeling more powerful and finding gratification in that feeling, powerful social roles (including some occupations) provide opportunities and incentives for impact on others. Such occupations usually require actual power behavior and reward skill at using power.

The motives are thought to tap dispositions and processes operating outside of conscious awareness; therefore, they have been termed "implicit motives" (McClelland, Koestner \& Weinberger, 1989, p. 690). The motives tend to "predict spontaneous behavioural trends over time" and are expressed in terms of needs like need for power (n-power) (McClelland et.al. 1989; McClelland,1975). This n-power can only be satisfied when one is able to make decisions or take actions that affect others lives (McClelland,1975, Winter,1973, 1992). Although power typically has been cast in a dark shadow, some have urged that the motivation of power can drive pro-social influence as well (Magee \& Langer, 2008). Need for power is thought to have a profound effect on thought and behavior. 


\section{Women's Desire for Freedom and Power Motive: A Study}

The concept of women power threw up a host of contradictions and inconsistencies as the sex role continues to be undefined and ambiguous. Power among women has only recently received attention of social scientists. Recent literature has shown that among women, power motive interacts with sex-role conception or style of self-definition and other social roles (Steward \& Winter, 1976). McClelland (1975) suggests that the traditional female role accentuates the power motivated women's concern with building up her resources in order to be more powerful (rather than to act powerfully) a concern was focused particularly on the body and its discipline.

Women power can possibly be defined in terms of two dimension-attitude and belief-which are not mutually exclusive. It consists of the extent to which women express their likes and dislikes towards power behavior as well as their belief towards social system, i.e., when, how, over whom, for what goals and with what constrains it should be exercised. To be considered as a dimension of individual differences, power has to be defined in terms of such factors as aggression, dominance, assertiveness, self-consciousness, internal control, leadership and so forth.

By and large, roles of women are changing day by day in the modern world. Women are altering their roles or life purposes from traditional areas to nontraditional areas that, in turn, reflects role strain and role conflict within the families and societies. Here, we are concerned how the women power is expressed by the women. Since most of the cultures are governed by the "male chauvinism", women have fewer opportunities for expressing power or the need for power because of the fear of power or the threat from traditional roles. Falbo \& Peplau (1980) suggests that females are more likely to resort to using indirect influence strategies because they feel they do not have sufficient power to use direct strategies. They found that the influence strategies students used with intimate partners would be characterized along the dimensions of directedness and bilaterally. Females used unilateral and direct strategies such as non-compliance, withdrawal and negative effect. If a woman does not use direct power, she may risk being labeled pushy or overbearing. Falbo, Hazen \& Linimon (1982) have conducted an experiment where females were assigned both direct and indirect power options, females were evaluated less favourable and seen as less competent when using more direct approaches. Thus, in power positions women may not choose to wield power directly, but may accept that options rather than facing the aversive consequences associated with the use of more "masculine" behaviors.

Although, most of the researches carried out in the area of power motive on men, the genders do not differ in average levels of power motives (reviewed in Stewart \& Chester,1982), and high power motive among women tend to choose and enter the same carriers as high power motive men (Winter, 1988).

Similarly, Singh (1986) found in his studies on Indian college students that subjects higher in need for power tended to be reserved, forthright, trusting, conservative, adherent, interested in 


\section{Women's Desire for Freedom and Power Motive: A Study}

people and not much interested in money. Corroll (1987) examined the relationship of power motive with narcissism, affiliation and intimacy and found that power motive is significantly and positively related to narcissism and need for intimacy. The survey of researches on power motive by psychologists and sociologists gives an impression that power motive has been considered as an important variable which has significant impact on human personality, human activities and interpersonal interaction. But studies on power motive of women with reference to their desire for social freedom have not been done. There is a lack of researches in the area of women's desire for social freedom and need for power motive. Women's with lower level of WSF are having tradition attitude and higher level of WSF are expressed modern views and having a strong urge of power motive.

In addition, psychologists have tried to study socio-psychological factors associated with the urge for social freedom in women. Verma, (1995) has investigated the relationship of WSF with some needs such as achievement, affiliation, change etc. and also with instrumental and terminal values. Sah, (1995) has explored the relation of some personality factors such as self concept, intolerance for ambiguity, adjustment etc., with WSF. In a few study WSF of women of organised and unorganised sector of social life have also been explored (M. Sah, 2002). But WSF in relation to power motive has not been explored.

\section{Purpose of the study}

The main purpose of the present study was to measure the level of women's desire for social freedom, need for power motive among college going girls and also determine the relationship between women's desire for social freedom and the level of power motive.

\section{Objectives of the study:}

- $\quad$ To measure the level of WSF among educated girls.

- $\quad$ To study the power motive among educated girls.

- $\quad$ To study how WSF and power motive in educated girls are link together.

\section{Hypothesis}

Based on literature review a few hypotheses were formulated and tested:

1. Women with strong desire for social freedom will be scored high on power motive Inventory.

2. Women with high and low WSF will differ with respect to their need for power.

3. Women desire for social freedom and urge for power would be positively correlated.

\section{THE RESEARCH STRATEGY}

\section{The Coverage and Setting}

The sample of the present study consists of 200 educated girls from 18 to 26 yrs of age, studying $1^{\text {st }}$ year of college up to the Ph.D. degree from different degree colleges \& P.G. departments at

(C) The International Journal of Indian Psychology, ISSN 2348-5396 (e)| ISSN: 2349-3429 (p) | 178 
T.M. Bhagalpur University. They were selected through purposive sampling technique with the help of admission \& attendance register of the college. All the respondents were regular students and belong from lower and middle class families.

\section{Tools used:}

1. Women's desire for social freedom (WSF) Scale-A Hindi version of WSF scale developed by M. Sah which includes 24 items had been used in this study. This scale cover WSF in the area like parental and husband control, social customs, rituals and taboos, marriage, bondage, economic independence and interference to occupational choice etc. The higher score indicates strong desire for freedom.

2. $\quad$ Power Motive Scale-Power Motivation Inventory (PMI) developed by H. Ojha (1979) which includes 30 items had been used. This inventory is related to four ways of experiencing power motive as identified by McClelland (1975), they are-deriving power through connection with significant others, acquiring power through possession of wealth self-discipline, displaying power through self-assertion and helping behaviour and gaining power through acting as an agent of higher institutions and higher authorities. The higher score on this scale indicates a higher level of power motivation and low score indicates a lower level of power motive.

\section{RESULTS AND DISCUSSION}

The obtained data were analyzed and presented in the tabular form in the light of the objectives and hypothesis of the research.

Table1: Comparison of power motive scores of the high and low WSF group

\begin{tabular}{|c|c|c|c|c|c|c|c|}
\hline Group & $\mathbf{N}$ & $\mathbf{M}$ & SD & SE & t-value & df & p-value \\
\cline { 1 - 6 } High WSF & 32 & 28.56 & 2.51 & .44 & 29.44 & 83 & $\mathrm{P}<.01$ \\
\hline
\end{tabular}

Women's having WSF scores above the third quartile point (Q3) were categorized in the high WSF group and the women's having WSF scores falling below the lower quartile point were categorized in the low WSF group. Table 4 shows the comparison of power motive scores of the high and low WSF groups. Results indicate that the women's having high score on WSF also had strong urge of power motive as compared to low WSF group. Thus the hypothesis no.1 is accepted.

It was hypothesized that women's with high and low WSF score will differ significantly with respect to their need for power motive. It is apparent from the table 1 that the t-value (29.44) is significant at .01 level. This shows that there was a significant differences between the mean power motive scores of the two groups in which the women's of high WSF had a higher mean than the women's of low WSF group. The careful scrutiny of this data revealed that only $16 \%($ 32) girls were scored in the upper quartile range (Q3) whilst $26.5 \%$ (53) girls scored below lower quartile range $(\mathrm{Q} 1)$.

(C) The International Journal of Indian Psychology, ISSN 2348-5396 (e) | ISSN: 2349-3429 (p) | 179 
Women's Desire for Freedom and Power Motive: A Study

Table 2: Relationship between WSF and power motive scores

\begin{tabular}{|c|c|c|c|c|c|c|}
\hline Dimension & $\mathbf{N}$ & $\mathbf{M}$ & SD & $\mathbf{R}$ & Df & p-value \\
\hline WSF & 200 & 15.03 & 1.21 & .886 & 198 & $\mathrm{P}<.01$ \\
\hline PMI & 200 & 18.49 & 1.35 & & & \\
\hline
\end{tabular}

It was hypothesized that the scores of WSF and power motive will be positively correlated. The values of obtained mean, SD and correlation co-efficient between WSF and power motive are presented in table 2.

From inspection of table 2 it is apparent that the average WSF score of educated girls is 15.03, with a SD of 1.21, which indicates the moderate level of women's desire for freedom. The average power motive score is 18.49 with a SD of 1.35 , which indicates also the moderate urges of power motive. Results also show that the obtained co-efficient of correlation between the scores of WSF and power motive among women is positive and significant at .01 level. Thus, the results are in complete accord with the earlier findings recorded by some of the investigators (Nazmi \& Ahmad, 2005; Mishra \& Singh, 2015 ).

\section{CONCLUSION}

The findings of the study clearly indicate that all the respondents were expressed moderate level of WSF and eager to uplift their social status equal to men. They were also expressed moderate urge of power motive. These findings correspond with other research findings. There is no denying the fact that women in India have made a considerable progress in the last fifty years, but yet they have to struggle against many handicaps and social evils in the male dominated society. It also confirm to the image of women in a changing scenario. The liberating effect of economic independence and social change is revolutionizing their lives enormously. Hence, it is needless to say industrialization, globalization and liberalization has made a tremendous impact on women's status and empowerment.

\section{REFERENCES}

Jenkins, S.R. (1994). Need for Power and Women’s Carriers Over 14 years: Structural Power, Job Satisfaction and Motive Change. Journal of Personality and Social Psychology. Vol. 66, No. 1, P. 155-165.

Jyoti, J.; Sharms, J \& Kumari, Anita. (2011). Factors affecting Orientation and Satisfaction of Women Entrepreneurs in Rural India. Annals of Innovation \& Entrepreneurs. Vol. 2, No. 1.

Mishra, K.K. \& Singh. J. (2015). Does Power and Approval Motives Regulate Adolescents' Altruism? The International Journal of Indian Psychology. Vol. 2, Issue.2.

Nair, L.; Mani,A.; Mishra,P. \&Topalove,P. (2014).The Power of Political Voice:Women's Political Representation and Crime in India.

Nelson, K. \&Khan, A.S. (2014).Conservative Policies and Women's Power. The Journal of Sociology and Social Welfare. Vol.9. Issue.3, Pp. 435-449. 


\section{Women's Desire for Freedom and Power Motive: A Study}

Nizemi, N. \& Ahmad, R. (2005). Influence of Marital Status and Sex Role Orientation on Women Power. Journal of the Indian Academy of Applied Psychology. Vol. 31, No. 1-2., Pp. 29-36.

Phondej, W. \& Yousapronpaiboon. (2015). Linking Female Leaders' Personality Traits to Motives, Powers, and Behaviour Competencies: Women in Executive Level Positions. World Review of Business Research. Vol.\%, No. 3.Pp-247-258.

Prema, S. \& Venmathi, A. (2011). Empowerment of Women as Consumers Versus Advertisement. International Conference of Social Science and Humanity. Vol.5.

Rachel,Z.B., Caroler, R. \& Doreen, C. (1984). Social Power Need and Gender Among College Students. Psychological Reports, Sage Publications. Vol.55, Issue. 1.

Ramsay,J.E.; Pang, J. S.; Ho \& Ho. (2016). Need for Power Predicts Carrier Intent in University Students. Journal of Carrier Assessment. Sage Publications. Impact Factor 1.507.

Schultheiss, O. C. \& et al. (2005). Effects of Implicit Power Motivation on Men's and Women's Implicit Learning and Testosterone Changes After Social Victory or Defeat. Journal of Personality and Social Psychology. Vol.88, No. 1,Pp. 174-188.

Sinha, R.(2013). Status of Women in India. IIAIEIA, Human Rights.

Sokolowsky, K; Schmalt, H.; Thomas, A. L. \& Puca, R. M. (2000). Assessing Achievement, Affiliation and Power Motives All at Once: The Multi-motive Grid (MMG). Journal of Personality Assessment. 74(1), 126-145.

Winter,D.G. (1988). The Power Motive in Women—and Men. Journal of Personality and Social Psychology. Vol. 54(3).Pp. 510-519.

How to cite this article: L Pandey, B Shabila (2016), Women's Desire for Freedom and Power Motive: A Study, International Journal of Indian Psychology, Volume 3, Issue 3, No. 11, DIP: 18.01.208/20160303, ISBN: 978-1-365-21307-6 